\title{
Histopathological spectrum of endometrium in abnormal uterine bleeding
}

\author{
Simridhi Bindroo ${ }^{1}$, Monika Garg ${ }^{2 *}$, Tajinder Kaur ${ }^{3}$
}

\begin{abstract}
${ }^{1}$ Department of Pathology, MM Medical College and Hospital, Solan, Himachal Pradesh, India
${ }^{2}$ Department of Pathology, ${ }^{3}$ Department of Obstetrics and Gynecology, MM Institute of Medical Sciences and Research, Mullana, Ambala, Haryana, India
\end{abstract}

Received: 18 June 2018

Accepted: 24 July 2018

*Correspondence:

Dr. Monika Garg,

E-mail: monikakash7@yahoo.co.in

Copyright: () the author(s), publisher and licensee Medip Academy. This is an open-access article distributed under the terms of the Creative Commons Attribution Non-Commercial License, which permits unrestricted non-commercial use, distribution, and reproduction in any medium, provided the original work is properly cited.

\section{ABSTRACT}

Background: Abnormal uterine bleeding (AUB) interferes with the quality of life of an otherwise healthy woman. Until the pathology underlying menorrhagia is, accurately diagnosed, proper therapy is hardly possible. The objective of the study was to analyze different histopathological patterns of endometrium in AUB and observe the incidence of various pathologies in different age groups and their relation to parity.

Methods: This two-year prospective studywas done in the department of pathology in atertiary care centre, which included 250 cases of clinically diagnosed AUB patients were evaluated. Histopathological examination of endometrial biopsies and hysterectomy specimens were done, followed by clinical correlation.

Results: Out of 250 cases of AUB, Premenopausal bleeding was seen in 216 cases $(86.4 \%)$ and 34 cases (13.6\%) had postmenopausal bleeding. The commonest finding observed in the study was proliferative phase endometrium (37.2\%), followed by secretory endometrium $(34 \%)$ and endometrial hyperplasia (16\%). Disordered proliferative endometrium was seen in $2.4 \%$ of patients. Endometrial carcinoma was seen in 4 (1.6\%) cases. Endometrial hyperplasia was seen mostly in the age group 41-50 years (27 cases). Two cases of endometrial carcinomas were presented after age 60 years.

Conclusions: Our study revealed the highest incidence of AUB in the perimenopausal age group (41-50 years). Hence a thorough histopathological workup and clinical correlation are mandatory in cases of abnormal uterine bleeding.

Keywords: Endometrium, Hyperplasia, Hysterectomy, Menopause, Menorrhagia, Uterine hemorrhage

\section{INTRODUCTION}

The endometrium is a dynamic, hormonally sensitive and responsive tissue, which constantly and rhythmically undergoes changes in the active reproductive life. Abnormal uterine bleeding (AUB) is one of the commonest complaints leading to endometrial sampling by endometrial curettage. It affects $10-30 \%$ of reproductive-aged women and upto $50 \%$ of perimenopausal women. ${ }^{1}$
Abnormal uterine bleeding may be defined as a bleeding pattern that differs in frequency, duration and amount from a bleeding pattern observed during a normal menstrual cycle or after menopause. ${ }^{2}$ Abnormal uterine bleeding can present as menorrhagia, metrorrhagia, polymenorrhea, metromenorrhagia, perimenopausal and postmenopausal bleeding. ${ }^{3}$

Abnormal uterine bleeding interferes with the quality of life of an otherwise healthy woman. In order to evaluate endometrial samples, information regarding age, the 
phase of her menstrual cycle, and use of any exogenous hormones along with clinical examination are a prerequisite. Patients with a history of anovulation, obesity, hypertension, diabetes, and exogenous estrogen use are at an increased risk for hyperplasia and adenocarcinoma. The importance of endometrial curettage done to obtain material for histopathological evaluation to aid in diagnosis and further management cannot be overemphasized especially inperimenopausal and postmenopausal age groups.

In this study, we have attempted to analyze different histopathological patterns of endometrium in AUBand observe the incidence of various pathologies in different age groups and their relation to parity.

\section{METHODS}

This two-year prospective studywas done in the department of pathology in a tertiary care centre, which included 250 cases of clinically diagnosed AUB. Patients with a gestational cause, isolated cervical or vaginal pathology, leiomyoma, pregnancy-related complications, bleeding due to previously diagnosed gynaecological malignancy, hemostatic disorders and autolysed specimenswere excluded. Consent was taken from the ethical committee of the institute prior to the commencement of the study. Detailed clinical history including age, pattern and duration of abnormal bleeding, menstrual history, obstetric history, use of exogenous hormones, physical examination findings including pelvic examination and investigations were recorded. The pattern of the bleeding was classified as menorrhagia, metrorrhagia, polymenorrhagia, metromenorrhagia, periand postmenopausal bleeding. The specimens were received as endometrial curettage, endometrial biopsy and hysterectomy specimens. All specimens were fixed in $10 \%$ formalin. After detailed gross examination, paraffin blocks of tissue were made; sections were cut and stained with hematoxylin and eosin. Histopathological examination of endometrial biopsies and hysterectomy specimens were done, followed by clinical correlation. The functional causes of AUB included in this study were normal cyclical phases (proliferative and secretory) of the endometrium and other abnormal physiological changes in the endometrium (atrophic endometrium, weakly proliferative endometrium, disordered proliferative endometrium and pill endometrium). Organic intrauterine lesions, which were the cause of AUB in this study, include chronic endometritis, hyperplasia, and endometrial carcinoma.

\section{RESULTS}

The presentstudy has been conducted on 250 specimens of the endometrium (endometrial curettings/biopsy and hysterectomy specimens) received in the Pathology Department of a rural tertiary care institution, with the clinical diagnosis of abnormal uterine bleeding.



Figure 1: Patterns seen in majority of premenopausal endometrium. (A) Proliferative endometrium showing pseudo stratification, H\&E 400X. (B) Secretory endometrium showing tortuous glands, H\&E 100X.

(C) Disordered endometrium showing cystically dilated glands along with proliferative glands with loose oedematous stroma, H\&E 100X. (D) Chronic endometritis showing plasma cells in the endometrial stroma, H\&E 400X.
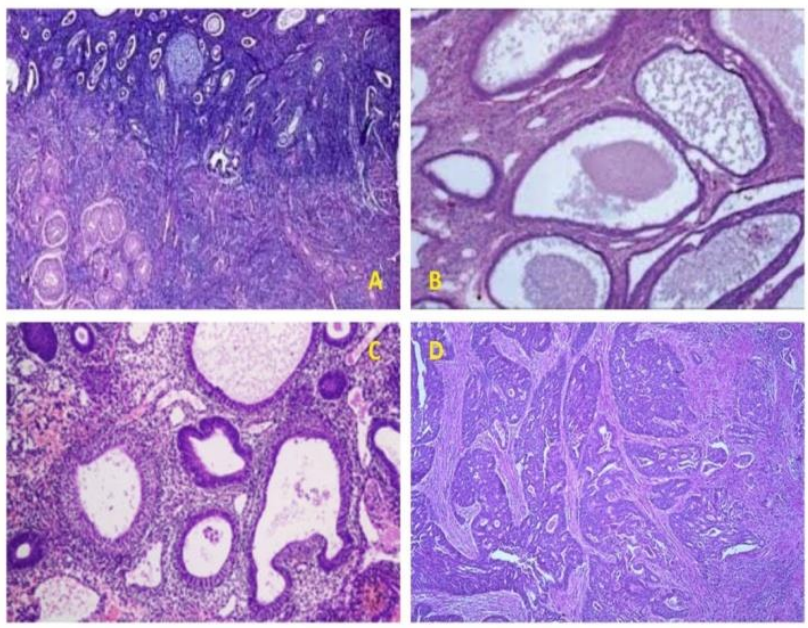

Figure 2: Patterns seen in majority of postmenopausal endometrium. (A) Senile cystic atrophy showing atrophic glands with cystic change, H\&E 100X. (B)

Simple cystic endometrial hyperplasia showing increased gland to stroma ratio with cystically dilated glands, H\&E 100X. (C) Complex endometrial hyperplasia without atypia showing increased gland to stroma ratio with tufting and budding of endometrial glands, H\&E 100X. (D) Endometrial carcinoma, H\&E $100 X$.

Patients' age ranged from 19-70 years and most of them were seen in the age group of 41-50 years, followed by 31-40 years. The commonest complaint was menorrhagia in 127 patients $(51 \%)$ followed by metrorrhagia (10\%), menometrorrhagia (9\%), poly-menorrhoea $(7 \%)$, polymenorrhagia $(4 \%)$, continuous bleeding $(3.4 \%)$, oligomenorrhoea $(2 \%)$ and post-menopausal bleeding (13.6\%). 
Majority (50\%) of the patients were multiparous (para 34). $14.8 \%$ of cases were of low parity (para 1-2) and $7.6 \%$ were nulliparous. Premenopausal bleeding was seen in 216 cases $(86.4 \%)$ and 34 cases $(13.6 \%)$ had postmenopausal bleeding. Out of 216 cases of abnormal uterine bleeding in premenopausal group (Figure 1), maximum $(43 \%)$ endometrial patterns were of proliferative endometrium followed by secretory $39.35 \%$, hyperplastic $13.42 \%$, disordered endometrium $2.3 \%$, endometrial stromal sarcoma $0.92 \%$, pill endometrium
$0.46 \%$ and chronic endometritis $0.46 \%$. Similarly out of 34 cases of the postmenopausal bleeding group (Figure 2), maximum 18 (52.94\%) were of atrophic endometrium followed by hyperplastic endometrium 11cases $(32.36 \%)$. Endometrial carcinoma constituted $5.9 \%$ in the postmenopausal group while disordered endometrium, pill endometrium and chronic endometritis each constituted $2.94 \%$ (Table 1 ).

Table 1: Distribution of cases of abnormal uterine bleeding.

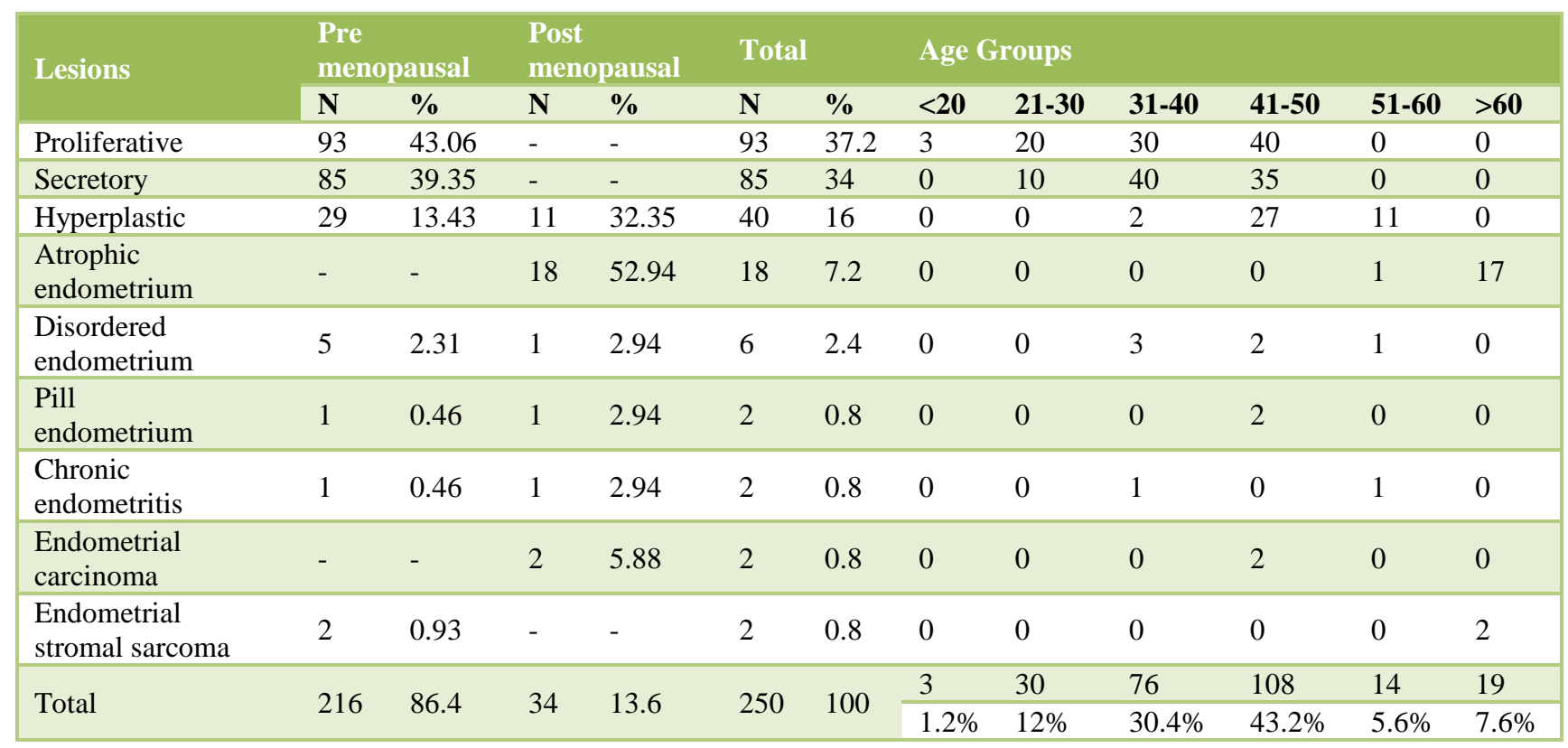

The commonest findings observed in the study was proliferative phase endometrium $(37.2 \%)$, followed by secretory endometrium (34\%) and endometrial hyperplasia $(16 \%)$. Disordered proliferative endometrium was seen in $2.4 \%$ of the patients.

Endometrial carcinoma was seen in four (1.6\%) cases. Amongst 40 cases of hyperplasia, 34 cases were of simple hyperplasia without atypia (85\%), 3 cases each of simple atypical hyperplasia (7.5\%) and complex hyperplasia without atypia (7.5\%) and no case of complex atypical hyperplasia.

Between 31-40 years, the secretory pattern was the most common (40 cases) followed by proliferative change (30 cases). Endometrial hyperplasia was seen mostly in the age group 41-50 years (27 cases).In the 51-60 age group, endometrial hyperplasia was the most common pattern. Two cases of endometrial stromal sarcoma were seen in the age group between 41-50 years i.e. perimenopausal age group. Two cases of endometrial carcinomas were presented after age 60 years.

\section{DISCUSSION}

Abnormal uterine bleeding is a commonly encountered gynaecological problem. It interferes significantly with the quality of life in otherwise healthy women with various distressing symptoms like menorrhagia, polymenorrhea and metrorrhagia. AUB includes both dysfunctional uterine bleeding (DUB) and bleeding from structural causes. Dysfunctional uterine bleeding is defined as abnormal uterine bleeding without a demonstrable organic cause. In most instances, dysfunctional uterine bleeding is due to the occurrence of an anovulatory cycle. The mechanisms involved in anovulatory bleeding vary, but each reflects an abnormal pattern of steroid hormone stimulation, which may include estrogen breakthrough, estrogen withdrawal and progestin breakthrough bleeding. It can be diagnosed after exclusion of structural, iatrogenic, medications, psychological and systemic disorders by various diagnostic techniques. 
In the present study, maximum specimens were of endometrial curettings $(46.8 \%)$ which iscomparable to thestudy by Bolde et al4 in which $58.2 \%$ endometrial sampleswere endometrial curettings. Endometrial curettage being a safe and easy procedure is the most common modality for diagnoses of endometrial pathologies a gradual increase in patients with respect to age was also observed in this study. The most common age group presenting with AUB in this study was 41-50 years. Similar observations were also made by Bolde et al,Vaidya et al, Doraiswami et al and Jairajpuri et al. ${ }^{4-7}$ An increased number of cases in this age group could be due to the fact that, as menopause approaches, decreased number of ovarian follicles and their increased resistance to gonadotrophic stimulation, results in low level of oestrogen which cannot keep the normal endometrium growing. Less number of patients seen in the higher age groups over 60 years may be due to earlier evaluation, detection as well as management of the disease. Our study and other studies found menorrhagia as the most common complaint. ${ }^{4,5,7,8}$ Most of our patients were in the multiparous category. Other studies also reported a higher incidence of AUB with increase in parity. ${ }^{8-10}$

Histopathological examination of the endometrial biopsies and curettings revealed various patterns ranging from physiological to pathological lesions of the endometrium. In the present study, the most common histopathological findings were proliferative phase followed by secretory phase endometrium. Proliferative and secretory phase endometrium was observed in $37.2 \%$ and $34 \%$ patients and was found the maximum in the age group of 41-50 years and 31-40 years respectively. Other studies reported incidences of $28.3 \%$ and $32 \% .6,11$ This pattern was commonly observed in the late reproductive and perimenopausal women in our study and other studies and may be due to the hormonal imbalance in this group leading to intermittent anovulatory cycles. Doraiswami et al also showed a predominant number of cases of AUB to be normal physiologic phases such as proliferative, secretory and atrophic menstrual pattern. ${ }^{6}$ The bleeding in the proliferative phase may be due to anovulatory cycles and bleeding in the secretory phase is due to ovulatory dysfunctional uterine bleeding. The bleeding in secretory phase is due to ovulatory dysfunctional uterine bleeding and the main defect is in the control of processes regulating the volume of blood loss during the menstrual breakdown of the endometrium. Thus bleeding is characterized by regular episodes of heavy menstrual blood loss or menorrhagia.

Disordered proliferative pattern lies at one end of the spectrum of proliferative lesions of the endometrium that includes carcinoma at the other end with intervening stages of hyperplasia. It differs from the normal proliferative endometrium in the absence of uniform glandular development but is not abnormal enough to be consideredhyperplastic. Disordered proliferative patterns resemble a simple hyperplasia, but the process is focal rather than diffuse. Diagnosing the patients at the earliest stage of this spectrum will be of definitive help to the practicing gynaecologists to prevent the disease progression. In this study $2.4 \%$ cases were seen while literature reveals $5.7 \%$ to $20.54 \%$ cases. ${ }^{6,7,12,13}$ Endometrial hyperplasia is a precursor of endometrial cancer. It is more commonly seen during the perimenopausal period. As endometrial hyperplasia is a precursor of endometrial cancer, with overall risk of progression to cancer being $5-10 \%$, its identification is important in peri and postmenopausal patients presenting with AUB. The classification used by the World Health Organization (WHO) designates four different types of hyperplasia. Hyperplasia is classified as simple or complex based on the absence or presence of architectural abnormalities such as glandular complexity and crowding. They are further designated as atypical if they demonstrate nuclear atypia. In this study, hyperplasiawas seen in $16 \%$ cases andwas seen mostly in the age group 41-50 years (27 cases). In some studies similar age group patterns is seen by authors. ${ }^{13-15}$ Abnormal and excessive endometrial bleeding occurs in reproductive women of all age groups but is more common in adolescent and perimenopausal women. Similar to the data in other studies the incidence of hyperplasia peaked in the perimenopausal age group. Endometrial carcinoma can occur can a result of excess estrogenic stimulation and developing against a background of endometrial hyperplasia or de novo combined with insufficient progesterone levels. Endometrioid endometrial carcinoma is the most common form of endometrial cancer. In our study two cases of endometrial stromal sarcoma were noted both in 41-50 years of age group. Both the patients presented with menorrhagia and mass in the pelvis. In a previously reported study of 14 cases of low grade ESS, the most common presentation was vaginal bleed $(86 \%)$, followed by pelvic mass $(7 \%)$ and pelvic pain $(7 \%) .{ }^{16}$ Two cases of endometrioid endometrial adenocarcinomawith villoglandular pattern was seen in postmenopausal women. As reported in the literatureendometrial carcinoma was also commonly seen in the postmenopausal age group in our study. ${ }^{3-6,15}$ Nulliparity, increased body mass index, and chronic anovulation have been implicated as risk factors for endometrial carcinoma. Effects of exogenous hormones (pill endometrium) were seen in only in $2(0.8 \%)$ cases and in 41-50 years of age group similar to seen by other authors $(1.7 \%-4.81 \%)$ and was seen mainly in perimenopausal age group. ${ }^{5,7}$ In this pattern, the endometrium shows a combination of inactive glands, abortive secretions, decidual reaction, and thin blood vessels. This may be attributed to the fact that, increased numbers of patients in this age usually seek for early medical management for bleeding. Atrophic endometrium was seen in 18 cases (7.2\%) out of which 17 cases occurred $>60$ years of age similar to other reports. ${ }^{6,7}$ Atrophy of endometrium occurs as consequence of the prolonged absence of any endogenous or exogenous estrogenic stimulation. The thin atrophic endometrium is susceptible to trivial trauma, which may be responsible for postmenopausal bleeding 
even in the absence of identifiable lesion. Superficial large venules are situated under a thin endometrium, which may rupture to cause excessive uterine bleeding. Chronic endometritis was seen in 2 cases $(0.8 \%)$ one at 33 and other at 52 years of age similar to study done by Sandeepa et al $(1.88 \%) .{ }^{17}$

\section{CONCLUSION}

The present study showed that the highest incidence of AUB is in the perimenopausal age group (41-50 years). Hence a thorough histopathological workup and clinical correlation is mandatory in cases of abnormal uterine bleeding for appropriate therapy and to avoid further complications.

\section{ACKNOWLEDGMENTS}

Authors would like to thank Dr. Nirupam, Dr. Khanna for their support during study.

\section{Funding: No funding sources}

Conflict of interest: None declared

Ethical approval: The study was approved by the Institutional Ethics Committee

\section{REFERENCES}

1. Sedhai LB, Shrestha A. Abnormal uterine bleeding; its prevalence, causes and management in Chitwan. J Chitwan Med Coll. 2012;1(2):36-8.

2. Al-Neaimy WMT, Ahmed MT, Al-Jawadi SI. Histopathological Interpretation of Abnormal Uterine Bleeding After the Age of 40 Year. Iraqi Postgrad Med J. 2010;9(3):274-82.

3. Sajitha K, Padma SK, Shetty KJ, Kishan Prasad HL, Permi HS, Hegde P. Study of histopathological patterns of endometrium in abnormal uterine bleeding. Chrismed J Health Res. 2014;1(2):76-81.

4. Bolde SA, Pudale SS, Pandit GA, Matkari PP. Histopathological study of endometrium in cases of abnormal uterine bleeding. Int J Res Med Sci. 2017 Jan 26;2(4):1378--81.

5. Vaidya S, Lakhey M, Vaidya SA, Sharma PK, Hirachand S, Lama S, et al. Histopathological pattern of abnormal uterine bleeding in endometrial biopsies. Nepal Med Coll J. 2013 Mar;15(1):74-7.

6. Doraiswami S, Johnson T, Rao S, Rajkumar A, Vijayaraghavan J, Panicker VK. Study of Endometrial Pathology in Abnormal Uterine Bleeding. J Obstet Gynaecol India. 2011 Aug;61(4):426-30.
7. Jairajpuri ZS, Rana S, Jetley S. Atypical uterine bleeding-Histopathological audit of endometrium A study of 638 cases. Al Ameen J Med Sci. 2013;6(1):21-8.

8. Khan S, Hameed S, Umber A. Histopathological Pattern of Endometrium on Diagnostic D \& C in Patients with Abnormal Uterine Bleeding. Ann King Edw Med Univ. 2011;17(2):166.

9. Patil SG, Bhute SB, Inamdar SA, Acharya NS, Shrivastava DS. Role of Diagnostic Hysteroscopy in Abnormal Uterine Bleeding and its Histopathologic Correlation. J Gynecol Endosc Surg. 2009;1(2):98104.

10. Corniţescu FI, Tănase F, Simionescu C, Iliescu D. Clinical, histopathological and therapeutic considerations in non-neoplastic abnormal uterine bleeding in menopause transition. Rom J Morphol Embryol. 2011;52(3):759-65.

11. Perveen S, Perveen S. Endometrium histology in abnormal uterine bleeding. Med Channel. 2011;17(4):68-70.

12. Gon S, Kundu T, Mallick D, Ghosh G. A Study on histopathological patterns of endometrium in different types of abnormal uterine bleeding among peri and postmenopausal women. IOSR J Dent Med Sci. 2016 Sep;15(09):106-11.

13. Abdullah LS, Bondagji NS. Histopathological pattern of endometrial sampling performed for abnormal uterine bleeding. Bahrain Med Bull. 2011 Dec;33(4):195-8.

14. Sajeetha KR, Anuradha M. Endometrial patterns in abnormal uterine bleeding: a retrospective study. Int J Reprod Contracept Obstet Gynecol. 2017 Oct 28;6(11):4966-70.

15. Bhatta S, Sinha AK. Histopathological study of endometrium in abnormal uterine bleeding. J Pathol Nepal. 2012 Sep 25;2(4):297-300.

16. Ashraf-Ganjoei T, Behtash N, Shariat M, Mosavi A. Low grade endometrial stromal sarcoma of uterine corpus, a clinico-pathological and survey study in 14 cases. World J Surg Oncol. 2006 Aug 9;4:50.

17. Sandeepa S, Jayaprakash HT, Ashwini MC. Abnormal uterine bleeding: Histopathological patterns of endometrium in elderly. Indian J Pathol Oncol. 2016;3(4):662-4.

Cite this article as: Bindroo S, Garg M, Kaur T. Histopathological spectrum of endometrium in abnormal uterine bleeding. Int J Reprod Contracept Obstet Gynecol 2018;7:3633-7. 